\title{
Organize Your Assets
}

Your heirs can't get more than you own. What do you have? Take a few minutes to fill out the following checklist. Like most people, you'll find that you're probably worth more than you thought (so that's nice news). This checklist helps with the rest of the book, since it "personalizes" the following pages.

A few simple instructions: Put down the present fair market value of each asset, not what you paid for it; round off all figures to the nearest $\$ 1,000$; if you get stuck on an item, leave it until later.

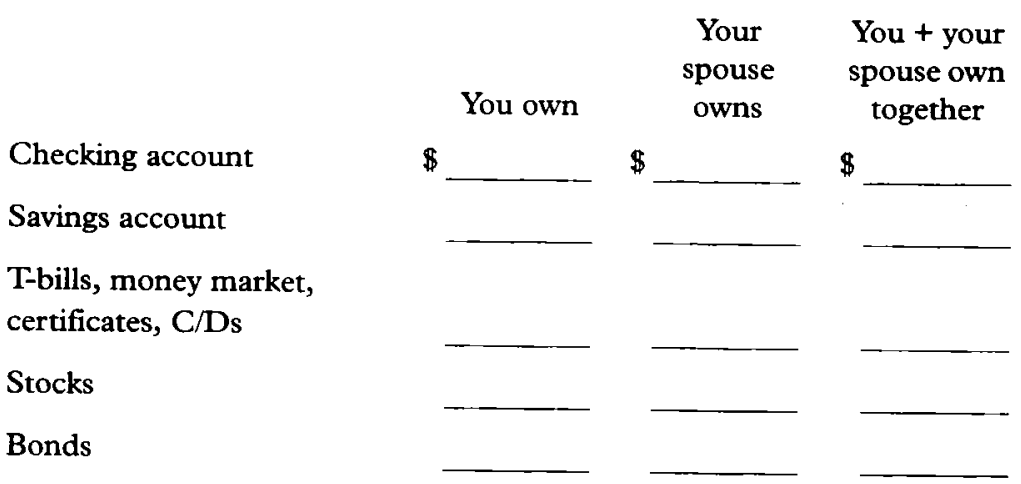


Residence

(subtract mortgage)

Other real estate (subtract mortgage)

IRA

Pension/profit sharing

Life insurance

Company-provided life insurance

Money owed to you

Deferred compensation

Automobiles

Jewelry

Household items

TOTAL
$\$$

You own
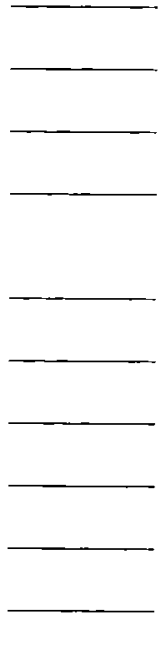

Your You + your spouse spouse own owns together

$\$$

$\$$ 